\title{
Learning from Friends: Developing appreciations for unknowing in reflexive practice
}

\author{
Stephen Allen \\ Hull University Business School \\ University of Hull \\ Hull, UK, HU6 7RX \\ Tel: 01482463541 \\ Email: stephen.allen@hull.ac.uk
}

\begin{abstract}
In this paper I develop a new perspective on being reflexive which appreciates unknowing as a core aspect. The intention is to promote more inclusive and equitable ways of managing and organising. By drawing on my own and others' experiences of the 'business method' of the Religious Society of Friends, or Quakers, images of the possibilities for reflexive practice which embrace individual unknowing and help foster systemic intelligence are explored. A relational ontology is pursued as these ideas can offer a suitable bridge to bring the processes of Quakers into conversation with debates about reflexive practice. The implication is that in the perspective developed, managing reflexively can be understood as a collective practice of searching for unity, or 'sense of the meeting', which is achieved through relational processes.
\end{abstract}

Key words: reflexivity, reflexive practice, Quakers, unknowing, group processes, spirituality

\section{Introduction}

I closed the door behind me. The room I had entered with its empty walls of exposed bricks and slatted wooden floor appeared less comfortable at night with the lights on. In the day even when it was gloomy the large window at the back and high windows around the top let in lots of light. In the room about ten people were sitting together in a semi-circle. They were facing two people sat at a table who next to them had an agenda penned on a flip chart. I had not been to this meeting before. Some welcomed me with smiles others were in conversation. I found a seat slightly to the side of the people in the semi-circle. Somewhat awkwardly I took out a pen and note book from my bag, trying to look like I might know how to conduct myself in this setting. After a while we became silent, this lasted for several minutes. The silence was closed by one of the people at the table standing up and explaining the agenda which had been agreed for the meeting. No deadline was set for our time together. Each item for discussion was introduced by one of the people sat at the table. This was followed by different people giving more background about the issue and/or sharing their thoughts about how we could address the situation. When anybody spoke they stood up. People tended to speak quite slowly and deliberately, giving a sense of concern about the topic under discussion, as well as for those who would potentially have responsibility for taking action if such a way forward was chosen. All listened in silence when others spoke. There was frequently a pause of up to a minute between different peoples' contributions. From time to time the two people at the table would seek reassurance that they were properly conducting the meeting from some of the 
people sat in the semi-circle. When there were no more contributions in relation to the item under consideration, one of the people sat at the table would begin to write. Everybody else was silent. When the pen stopped what had been written was briefly reviewed with the other person at the table, and then read out. On a few occasions this did not prompt more discussion and having produced a piece of text describing our view and a way forward we would begin on the next item of the agenda. On other occasions further discussion would include suggestions that what had been read was not reflective of their sense of what had been communicated within the prior discussion. Sometimes some additional text needed to be added to more clearly state what would be done, and by whom, in relation to the issue being considered. I made one such addition to an item which was about arrangements for using an organisation to take over the management of some of our financial accounting processes. When I stood up, I was surprised that I was hesitant and couldn't help my voice sounding nervous and a little stuttering. I felt a pressure that what I offered, like other contributions, needed to be said carefully with close attention to others' concerns. Once it was clear that all amendments had been suggested, there was more silence as the pen returned to the paper to revise the text. This process of refining the text could involve multiple cycles of further discussion and revision. Several hours passed before all agenda items had been completed and we found ourselves again in silence. After the silence ended most of us had further brief conversations before leaving the room.

This vignette takes us to the focus of this paper, the Quaker method of meeting for business, which is referred to by Quakers as the 'business method'. The progressive management practices associated with Quaker businesses have received some attention. For example the initiatives of Cadburys and Rowntrees in the early 20th century that improved the general living conditions of their employees by building them houses, schools and hospitals (e.g. Windsor, 1980). However, the Quaker business method and associated relational practices have received limited attention in management and organisational studies. My interest in these Quaker practices has developed from my family's attendance at weekly Quaker meetings over the past four years. The opening vignette is about my first involvement with the Quaker business method through attendance to a monthly Meeting for Business.

In this paper, by referring to my own experiences and those of other scholars and Quakers, I will explore how ideas about reflexive practice can be developed by considering what we can learn from the conduct and processes which inform the business method. I understand reflexive practice to involve two interconnected dimensions. Firstly, an ongoing attention to examining the assumptions and ethics which inform judgements about the morality, 'goods and bads', of different ways of (inter)acting (Barge, 2004; Bleakley, 1999; Cunliffe, 2004). Secondly, taking responsibility to create communicative opportunities so that (more) people are able to be actively engaged in the shaping of "new, more collaborative, and inclusive forms of reality” (Cunliffe, 2009, p. 409). In particular, I consider how because Quaker processes encourage unknowing - the "realisation of inadequacy to anything approaching full and comprehensive understanding” (Zembylas, 2005, p. 142) - they offer new possibilities for being reflexive. I am selecting the term unknowing because my interest is in exploring the dynamics of living and managing with the perpetual impossibility of individually knowing. This is distinctive from understanding a momentary state of not-knowing, or temporary ignorance, that can be overcome to achieve a full understanding of the situation or issue in focus. 
Although a core aspect of being reflexive involves actively engaging with the limits of our knowing, relating to issues of situatedness and perspectivity, unknowing has received limited attention. It is important to develop understanding of unknowing because it is associated with the disturbance and anxiety we can encounter when questioning our understanding and appreciating others' views, which can inhibit possibilities for managing reflexively (Antonacopoulou, 2004; Hibbert \& Cunliffe, 2015). Some scholars have sought to approach the issues of unknowing and bring attention to the limits of knowing, but give a sense that not-knowing can be individually worked through and potentially resolved (Marshall, 1999; Marshall \& Reason, 2007; Segal, 2010). I develop alternative possibilities for reflexive practice by arguing that appreciating an unresolvable unknowability is fundamentally important for being reflexive and can help promote more inclusive and equitable forms of managing and organising. By exploring the processes of unknowing involved in the Quaker business method I offer a new perspective on reflexive practice. I achieve this by using a 'relational ontology' (Gergen, 2009; Hosking, 2011) as a bridge to bring Quaker spirituality into conversation with discussions about reflexive practice. The implication of this perspective is that because bounded "constructing sovereign subject[s]" are decentered (Hosking, 2011, p. 51), being reflexive can be understood as involving practices of embracing individual unknowing so that collective knowing, or systemic intelligence, about being together in a world can be fostered.

I begin the paper by introducing ideas about reflexive practice, and explore how unknowing, which has received limited attention, is an important dimension for developing debates. To consider ways of embracing unknowing, I follow others who have taken a relational ontology informed approach to make connections between reflexive practice and spirituality. After this I introduce the Quakers and their spirituality, which leads into a discussion of the processes that constitute their business method. The concept of 'sense of the meeting' is then specifically explored as it underpins Quakers understanding of how they collectively find a way forward on any issue. Finally, I explain the ways Quaker processes can extend our understanding of practising unknowing, and how this informs a new perspective on managing reflexively.

\section{Reflexive practice and unknowing}

The idea of reflexivity has emerged from what has been described as a 'post-modern predicament', which relates to challenging modernist and positivist ideals that through our words we are able to fully represent the truth of an independent reality (Lawson, 1985). However, this predicament extends beyond the limitations of language for understanding the "flesh and blood and action" of our world (Bateson, 1979, p. 27), to also considering the implications of how our knowing is situated in time and place. We are of our "native roots" (Polanyi, 1962, p. 322). Reflexivity is suggested to be a conceptual resource which can help approach these ontological issues relating to language, situatedness and perspectivity. This is achieved as ideas of reflexivity promote possibilities for bending back on oneself, to inquire into the intricacies and complexities of interpretations which underlie our claims to knowing.

Within management and organisational studies, reflexivity has been debated in various streams of literature including: research methods, management identity, writing-up research and management education. Across these areas of research, ideas of reflexivity, which encompass significant variety, propagate questions about how to understand the status and meanings of our ways of knowing and producing knowledge. Some critics argue that the concept has limited value to enhancing our ways of understanding and acting by suggesting 
that being reflexive is unavoidable and a general human tendency (Lynch, 2000). Other scholars suggest that it has important implications for managerial practice (Barge, 2004; Bleakley, 1999; Cunliffe, 2009). They argue that managing reflexively involves engaging in processes to develop awareness of assumptions and other 'taken-for-granted' dynamics (Cunliffe, 2009), such as relations of powers (for example, perceptions of gender roles) and politics (for example, how people are socially valued who have roles at varying positions within an organisational hierarchy). As Hibbert and Cunliffe suggest, being reflexive involves "the realisation that we shape our lives with others; therefore, in shaping our lives, we need to be attuned to, and critically examine the circumstances of such relationships" (2015, p. 180). By surfacing assumptions and taking multiple perspectives, it is suggested that it is possible to understand more about how through our situatedness - socially, historically and physically - we can collude or contest dominant realities, such as the brief examples just mentioned. Consequently, being reflexive promotes "an explicit concern for 'otherness' and 'difference”” (Bleakley, 1999, p. 328), which implies that "reflexive practice becomes more than simply intellectual critique; it becomes a relational activity that involves a way of connecting with others" (Antonacopoulou, 2004, p. 71).

In discussions about reflexive practice several scholars have considered the potential disturbance that we can encounter when seeking to consider multiple perspectives and appreciate other peoples' views (Antonacopoulou, 2004; Hibbert \& Cunliffe, 2015; Segal, 2010). Such disorientation could be informed by opening up dialogue with people and being surprised by different and challenging views, which significantly depart from what you expected, or had previously been told, which tests your ability to relate and identify with them. Or, encountering an unfolding of uncertainties as reflexive questioning ruptures the possibilities for finding any firm and steady grounding within our views, so that we become left with the prospect of having to live with contradictory accounts and realities.

Moments of disturbance and disorientation have been conceptualised as relating to becoming 'struck' about what we are assuming and taking-for-granted (Corlett, 2013; Cunliffe, 2002).

Being 'struck' is seen to relate to an embodied (emotional, physiological, cognitive) understanding where we are "moved to change our ways of talking and acting" (Cunliffe, 2002, p. 42). Corlett (2013) suggests that noticing and paying attention to how we are struck, can prompt us to being reflexive about how we are interacting and interpreting. It is suggested that although "this disturbance [is] an invitation toward new understandings" and so is viewed as integral to reflexive practice (Hibbert \& Cunliffe, 2015, p. 182), it can be experienced as a personally unsettling encounter as reflexive practice can be found to be "difficult and painful” (Antonacopoulou, 2004, p. 61). However, although scholars acknowledge the potential for anxiety to overwhelm the possibility of being reflexive and promoting alternative ways of being and understanding, there has been limited attention to how to engage with this potentially inhibiting issue.

Segal (2010) explores reflexive practice and anxiety by drawing upon Heidegger's concept of 'resoluteness', which involves embracing powerlessness and dwelling with being lost. He suggests that resoluteness is a moment when "the anxiety of breakdown is transformed into the wonder of inquiry” where "disruptions in everyday management practices [are turned] into learning opportunities” (p. 381). Consequently, resolve is understood as the translation of feelings of anxiety into new understandings about ways of being in the world. Thus anxiety is seen to emerge when an individual is reflexively unsettled from their knowing into a feeling of not-knowing ('being lost'). Hence Segal's approach gives an idea of individual knowing which is punctuated with moments of not-knowing. 
Another way of appreciating and working with these complexities of being reflexive has been discussed by Marshall (1999). She describes her reflexive approach to being a person-scholar as about "beliefs, strategies, and ways of behaving which encourage [her] to treat little as fixed, finished, clear-cut", where being open to multiple perspectives is core to 'living life as inquiry' (Marshall, 1999, p. 156). This approach relates to ideas about action research where it is understood that "the inquirer is connected to, embedded in, the issues and field they are studying” (Marshall \& Reason, 2007, p. 368). Quality processes for 'taking an attitude of inquiry' are described as relating to "noticing how identity, ethnicity, class, our positioning in the world impact our research” (Marshall \& Reason, 2007, p. 369). However, although there is an attention to leaving (aspects of) situations and circumstances 'unprocessed' (Marshall, 1999) and "accept[ing] the limits of what we can know" (Marshall \& Reason, 2007, p. 372), these ideas, like Segal's writing, provide a sense that not-knowing tends to be temporal, which implies that it can be individually worked through and potentially resolved.

What I am proposing is a new perspective on reflexive practice where individual unknowing is embraced as a perpetual way of being, with knowing understood as emerging through the relationality of collective practices which draws upon peoples' differing perspectives, life histories and knowledges. This approach does not seek to eliminate individual anxiety and disturbance in understanding and developing reflexive practice which, as noted in discussions about reflexivity and social work, is likely integral to interaction and identity (Miehls, 2000). Nor, is it promoting a comforting way of being reflexive by trying to avert experiencing "confounding disruptions - at times even a failure of our language and practices" (Pillow, 2003, p. 192). But by embracing unknowing as an ongoing quality of individual existence, new possibilities can emerge about how we can be and understand together. As Zembylas suggests unknowing can be understood as "an act of embracing otherness" where "in the lack of knowledge, the meaning of its absence is found” (2005, p. 158).

Core to developing these ideas about reflexive practice is appreciating a view of knowledge as produced through relational processes. This is because, as explored, being reflexive involves interacting with others in ways that pay attention to how collective knowing and acting are shaped through relations. Recent discussions which have centred relational processes by decentring the individual knower, and so engaged with unknowability, have been considered in connection with ideas of relational ontologies.

\section{Unknowing and relational ontologies}

Gergen in his writing about the meanings and practice of a 'relational being' suggests that others are no longer the causes of our actions nor we the effects, but instead that "whenever we think, remember, create, and feel, we participate in relationship" (2009, p. 397). Hosking (2011), who also considers ideas of relational ontology, brings her ideas together under the label of 'relational constructionism'. Similarly to Gergen her approach does not centre a bounded "constructing sovereign subject" (p. 51). Instead ontology is given to relational processes. A key quality of understanding through a relational ontology is a focus on knowing emerging through collective practices (i.e. conversations and other interactions), rather than being about an individual's intellectual and cognitive activity.

Some scholars who have worked within a relational ontology have considered the implications for reflexive practice. Hosking and Pluut (2010) have described reflexive practice as relating to dialogic processes which enable collective turnings back on the topic or issue being considered. Keevers \& Treleaven suggest being reflexive is about "collective 
organizing practices” (2011, p. 518) which "encourage an attitude of inquiry and legitimize the willingness of being 'not knowing' in the presence of others" (p. 516). Such relationally engaged dialogue is suggested to involve promoting more equal arrangements of power as "emphasis shifts to ways of relating that make space for multiplicity, ongoing emergence and improvisation” (Hosking, 2012, p. 79). Hence, it can be understood that taking a relational ontologic approach "reconfigures reflexivity as situated, engaged, relational, materialdiscursive practices” (Keevers \& Treleaven, 2011, p. 506).

In relational ontology informed discussions about reflexive practice a key connection is to notions of spirituality. This is because, by decentering the individual knower, a need arises to seek to conceptualise and appreciate how to understand ourselves becoming together in a world; or, as spirituality has been defined, "some transcendent relationship with the divine and the universe” (Izak, 2009, p. 78). For example, Gergen argues that through taking an approach which centres relational processes there necessarily becomes a need to appreciate a spiritual dimension, as "that which contributes to the growth and extension of relational process acquires aspects of the divine" (2009, p. 392). He suggests that this is an idea of divinity which "is not distinct and distant [e.g. the conception of a remote God], but immanent in all human affairs” (Gergen, 2009, p. 393). Consequently, connections to spirituality offer a way of conceptualising and communicating how a relational ontologic approach means that our unknowing emerges through the socio-material interactions which we are seeking to know.

Gergen and Hosking (2006) have drawn upon Buddhist teaching to make connections between reflexivity and spirituality. In particular they explore 'Buddha nature' and how meditations of emptiness "provide the basis for being in the moment (nowness) open to what the situation might call for" (Gergen \& Hosking, 2006, p. 314). Such practices of meditation are suggested to help a person move away from a 'conventional mind' which is "very busy differentiating and solidifying self and other" (Hosking, 2012, p. 75) to "acting in a not knowing way" (p. 77, italics in original). These ideas also intersect with the work of Xing and Sims (2012) who consider reflexive practice in relation to the philosophical, ethical and religious tradition of Chinese Daoism. In particular, they explore the concept of Wu Wei which involves a "relaxed and serene state of one's mind or heart when following the flow of nature” (Xing \& Sims, 2012, p. 99). By relating to these aspects of Eastern thinking, Xing and Sims, although not within a relational ontology, explore similar themes to Gergen and Hosking's consideration of Buddhism. The connections include appreciating reflexive practice as involving being open to emergence and appreciating limited, or a lack of knowing about any situation.

I will explore how Quaker spirituality offers a way of appreciating how systemic interconnectivities within relations can inform our (un)knowing and action. Quakers like Buddhists tend not to worship a defined deity, instead understanding the divine to be present within human affairs. I am exploring, also using a relational ontology as a bridge to ideas of Quaker spirituality, the ways that their business method encourages individual unknowing and so can be understood as a means to achieve reflexivity. I show how Quaker spirituality and business method offer images of practices and a vocabulary to help to develop ideas about unknowing in reflexive practice. Consequently, to inform more inclusive and equitable forms of managing and organising this paper promotes critical attention on how collective understanding can emerge by fostering appreciations of divine interconnectivity. My interest is in 'critical spirituality' which as Bell describes offers possibilities for "enabl[ing] prevailing managerial orthodoxies to be challenged through the development of a practice- 
based morality” (2008, p. 295). I am not seeking to find ways to tap into a 'deep spiritual self'.

\section{Introducing the Quakers}

The Quakers, or Religious Society of Friends, are an international community of about 340,000 people (Dandelion, 2008). Quakers tend to refer to each other as Friends. They are often described as Nonconformist Christians, but differ significantly from other groups such as Baptists and Methodists. Quakers see living as sacramental where all life is appreciated as sacred, which means that concepts such as God or the divine relate to (aspects of) people and living beings, not a remote spirit (Durham, 2010). There is much variety between Quakers and Quaker Meetings as there is no creed, or statement of belief which is meant to be followed (Durham, 2010). Quakers are expected to find their own way to 'experimentally' know of divinity (Halliday, 1991), which means that "there is no need for priests to intercede” (Bradney \& Cownie, 2000, p. 49).

Although Quakers are non-credal, they are guided by four testimonies - equality, simplicity, truth and peace. 'Advices and Queries' is the opening section of the key Quaker book 'Faith and Practice', which offers accumulated insights in relation to these testimonies. The testimony of equality is perhaps the most important, with "everything that the Quakers stand for ... based around the same need to practice complete equality” (Durham, 2010, p. 10). This concern for equality can be seen, for example, by the ways that different roles are allocated. Nobody is 'in charge' and to avoid the development of hierarchies, and people becoming protective of their position, roles are rotated every three years.

A key distinction between Quaker Meetings (the name for each local group) is the different types of Meetings for Worship (the typically weekly gathering). 'Liberal' or 'unprogrammed' Quaker Meetings are grounded in the practice of silent worship and unplanned ministry, and 'programmed' tend to involve a pastor, hymns and prayers (Dandelion, 2008). The interest in this paper is with un-programmed, where during Meeting for Worship, Quakers gather in an unadorned room and "sit in silence together for an hour or so, standing up to speak only if they are led to do so, and then only to share some insight which they sense will be of value to others”, the meeting ends by shaking of hands (Ambler, 2013, p. 8).

By considering Quaker practice, I am specifically interested in what they describe as their business method. My key proposition is that approaches to practising reflexivity can benefit by learning from this method, because these approaches which appreciate equity in dialogue seek to foster systemic intelligence, by being closely attentive to the limitations of an individual's knowing. For example, as Kavanagh (2015) describes in her discussion of Quaker spirituality, the lack of specificity about what is God or divine is highly important for helping to promote appreciations for unknowing. This is because rationalised descriptions and definitions can unnecessary prescribe ways of understanding and being.

\section{Quaker business method}

The business method refers to the ways that Quakers have developed over the past 350 years to come together to make decisions in what are described as Meetings for Business, or Meetings for Church Affairs. The matters considered using this method can vary widely from administrative arrangements, such as how to organise processes for other groups to book and pay for using rooms in the Meeting House (the place Quakers go to meet), to the Meeting's position relating to global concerns such as the Transatlantic Trade and Investment Partnership. Key to understanding the approach in these meetings is that they share many of 
the practices of un-programmed Meetings for Worship, which reflects, as introduced, no distinction between the sacred and the secular. This means that meetings "not only begin and end with a period of silent worship, but at any time during the meeting anyone present can suggest that a further period of silence be held” (Bradney \& Cownie, 2000, p. 73).

As Doncaster explains "The Quaker method is not simply a technique; it is a faith which finds expression in a method” (1958, p. 73). A faith that in searching together as a gathered local community better outcomes will be achieved than anyone alone could have attained (Sheeran, 1983). Rack suggests an assumption underpinning this approach is that, "for every issue under consideration, there is a right or best outcome, and we all want to find it" (2002, p. 22). Quaker business method "enables decisions to be taken without majority voting, using spiritual discernment to come to conclusions which are never pressed by individuals" (Durham, 2010, p. 11). Bradney and Cownie explain that making decisions using spiritual discernment, means that they are "taken with the agreement of all present, in the light of God's guidance ... mean[ing] that everyone must feel it right to let the decision go ahead, even if there are bits of it which they might have expressed differently, or changed in some way” (2000, p. 71). God's guidance in this respect is about contemplatively investigating issues as a community. Ambler justifies Quaker spirituality by explaining that:

"Reason, thought and debate are very useful and often fair, but they are also limited when it comes to the deeper questions of life. They don't cope well with people's feelings either, or with the subtleties or personal relationships or group dynamics. These all have to be 'sensed' in a different way ... we go quiet and let a deeper, more sensitive awareness arise (2013, p. 67).”

From this introduction to Quakers and their business method, what can begin to be appreciated is how emerging from the various ideas about the divine in their worship and living, they need to be open to leadings, through and within their relations with others. Key to the design of the business method is Quakers recognising their individual limits and unknowing by being receptive to how "other Friends have different experience, different kinds of knowledge” (Ambler, 2013, p. 69). As Castle suggests, participating in the business method involves being "glad to see our limited ideas developed by those of others" (1961, p. 128). A core benefit of the method is by seeking to achieve 'unity', proposals are weighed by the group who will implement them (Sharman, 1983). Halliday describes how unity does not relate to conformity, but "concern for one another" which involves expressing, acknowledging and working with conflicting views to find a way forward for the community (1991, p. 13).

What I want to argue is how such an approach can offer images of possibilities for embracing unknowability, which I have suggested is a core and under-theorised dimension of ideas about reflexive practice. The Quaker idea of discernment has been explained as relating to a practice of equality and finding a unity between people. To explore how Quaker processes can be drawn upon to develop a new perspective on reflexive practice it is key to understand the concept of achieving 'sense of the meeting' which is central to the business method.

Morley (1993) suggests that it is crucial to understand achieving 'sense of the meeting' as distinct from consensus which other groups and organisations, such as some cooperatives, might seek to achieve. He explains how consensus relates to a secular process of people reasoning "in which we promulgate, argue, and select or compromise ideas” (Morley, 1993, p. 15) until an intellectually satisfactory decision is reached, "through consensus we decide 
it” (p. 5). However, 'sense of the meeting' is about sitting in unity where "we turn it over, allowing it to be decided" (p. 5), a commitment to being led based on faith in a relational power beyond each person, "where the decision is a by-product [that] happens along the way" (p. 15). Rack (2002) has conceptualised achieving sense of the meeting, or a 'gathered meeting', by relating it to Carl Jung's notion of collective unconsciousness. He uses Jung's concept to promote the idea that human beings can "communicate with each other at a deeper level, below the surface of consciousness" whereby communication is not mediated by words (Rack, 2002, p. 35). As Morley suggests "sense of the meeting hears all of the concerns, then moves beyond the verbal expressions to hear the spirit of the concern in order to discern what is 'right' for the group” (p. 6). It "requires listening rather than contending, weighing rather than reacting”' (p. 14).

In seeking sense of the meeting the role of the Clerk is highly important. It is a role which like others is rotated every three years. The variations between Quaker Meetings include differences in the role of the Clerk, but generally they are "an administrator and chair whose place is not to help to drive through resolutions, but rather to act as a channel through whom the Meeting's concerns and deliberations can pass” (Durham, 2010, p. 11). The Clerk also tends to be involved in preparing the agenda. Although discernment is every Friends' responsibility in the business method, it is the role of the Clerk to "draft a minute which accurately reflects the corporate view” (Bradney \& Cownie, 2000, p. 75). To create a minute the Clerk needs to discern where the will of the meeting is leading. In doing this "Clerks must be aware not only of what has been said, but also by whom it has been said, and also of the likely views of those who have remained silent; all this is not a simple matter of calculations, but a complex matter of judgement” (p. 75). The process involves the Clerk drafting a minute, in silence, at the end of discussion and then s/he reads it out. Alterations are made "until all present are satisfied that the minute accurately records the decision which has been taken” (p. 77). At this stage the minute can't be further amended. During this process, which can take some time, Clerks may intervene if anybody is speaking for too long, as well as ask the meeting to be silent, as can anybody else, if discussion becomes too heated, or to allow for a deeper unity to develop.

Morley (1993) suggests that three intertwined components are crucial in the process which leads to 'sense of the meeting'. These components can be understood as key aspects of embracing unknowing. Firstly, release where after an issue has been presented, "Friends should allow Friends whose feelings have been aroused to express those feelings. Friends who release their feelings should be listened to lovingly. No effort should be made to intervene - to correct, argue, analyse, criticise, clarify or explain away” (p. 14). This part of the process supports a 'clearing of the air' so that Friends can become more open for discerning on how to collectively move forward with the issue. Secondly, long focus which relates to ensuring the methods of coming and being together are respected and that progressing toward sense of the meeting is neither forced nor hurried. Finally, Transition to Light where a "long focus brings us to the Source of resolution and clarity" (p. 19, capital in original). This is described as sensing "an influx of enveloping harmony", where "we have arrived where we want to be" - a gathered meeting (p. 19). Morley argues that the nature of the issue and the feelings generated by it will determine how these three components become expressed.

\section{Reflexive practice and the business method}

The Quaker business method and 'sense of the meeting' have received limited attention in management and organisational studies. However, there have been some important 
contributions. Reis Louis (1994) explores the dynamics of a university appointments, promotion and tenure committee to consider what we can learn from Quaker processes to reinvigorate a sense of community for organisational renewal. She notices how "temper[ing] with willingness [her] own reflexive psychological orientation and the energetic (and enervating) problem solving which it entails” is central to group processes of sharing ownership and creating together (Reis Louis, 1994, p. 53). This is because working in this way, with humility, "suggests that the answer is not yet apparent and all are needed" (p. 53). She concludes that changing individual practice, to come together in the 'manner of Friends', can both contribute to and constitute organisational renewal through helping to deal with differences and fostering mutual respect.

Molina-Markham (2014) using a communication perspective analyses the silences in Quaker dialogue. Through her ethnographic analysis she examines the roles of different types of silence in achieving 'sense of the meeting', arguing that it can be understood "not as an absence or as the opposite of speech, but as a deeply meaningful communicative event" (Molina-Markham, 2014, p. 171). She suggests that silence is at the centre of Quaker processes of decision making, having a generative role which involves "the negotiation of difference through an indirect style that separated differing opinions in an interactional sequence" (p.171).

Law and Mol explore how Quaker practices can be understood as about 'fluidity', because they involve "giv[ing] up the habits of distinction", which, for example, challenge views that see individuals as distinguishable self-contained subjects (2003, p. 24). Consequently, their association of the metaphor of fluidity with the Quaker Way is about attempts "to accept, to loosen and to renounce the discrete and the countable” (Law \& Mol, 2003, p. 24). They consider the worshipping processes of Quakers to be about understanding "that there is more than can possibly be put into words" which involves an apprehension "to naming, delineating, dividing and measuring” (p. 25). It is in these ways that Quaker practices can show fluidity, which they explain as seeing the 'Other' or 'Otherness' (e.g. relating to indistinguishable boundaries between bodies) as "never mov[ing] away from the margins of vision, the corner of the eye, just unknowable, just beyond” (p 34, my italics). From their analysis Law and Mol suggest that the fluid qualities which they associate with Quaker processes can offer possibilities to engage in the often elusive and diffuse character of knowing how to organise in "heterogeneous worlds" (p.35).

In this paper, I am adding to these analyses of Quaker processes and spirituality, by further exploration of how the Quaker qualities and practices of humility, sharing ownership, silence and fluidity relate to being reflexive. In particular, learning from Quaker spirituality and associated business method, with its strong attention to equality, offers potential to develop the meanings and possibilities of reflexive practice. As has been explored by collectively seeking to discern the 'sense of the meeting' ways forward on a wide range of issues can be achieved by pursuing a relational unity to which each person present is constituent but subordinate. Through this process of meeting and being in dialogue, Quakers can be understood as not trying to individually grasp onto articulating a known way forward, but being open to proceeding in a practice of unknowing which can inform a collective knowing: or, to put it another way, seeking to foster a systemic intelligence, or "a wider group-wisdom" (Castle, 1961, p. 128). In the case of the Quakers these collective processes are underpinned by having spiritual appreciations of a relatively undefined divine whole.

Beyond these insights to promote possibilities for developing ideas of reflexive practice it is 
important to try to ground the explanation of the Quaker business method in an example. I have chosen to include a short example by Morley (1993, pp. 19-20) relating to Sandy Spring Meeting in Maryland USA. This is because, from reviewing Quaker writing, this example is one that is used across multiple sources, and hence can be understood as having explanatory value within Quaker communities about what they are seeking to achieve through the business method. As background to this example, part of the Quaker's testimony to peace means that they are typically pacifists.

I recall a business meeting which had almost concluded. The clerk asked for any new business. A woman rose and told how she had come down the lane to the Meeting House on the Memorial Day just past. She began to cry. Through her release she explained with quavering voice that she saw men with guns in the Quaker graveyard. "There are people buried in the graveyard who served in the military" someone said, interrupting her release. "The men were honouring them."

"But they were in my graveyard with guns," she said through tears.

Her release set off others who were equally distressed that men with guns should enter the graveyard. The meeting listened tenderly as other Friends spoke through their weeping.

Another Friend spoke up, this time in anger. "Who do those people think they are, walking into our graveyard with guns?”

Other angry voices were raised and listened to patiently.

"They're from veterans groups," someone explained. "They decorate the graves of veterans every Memorial Day."

Discussion shifted back and forth between concern about guns in the graveyard and the care that veterans took to remember other veterans. "After all," some said, "we knew they had served in the military when we allowed them to be buried there. In many cases it's on the gravestone."

"If a choice has to be made between Linda feeling as she does, and men with guns in the graveyard, that is not a difficult choice," said a Friend. By shifting concern from guns to Linda, from the issue to the sensibilities of a member of the meeting, he had begun to lengthen the focus.

Transition to Light came swiftly. "Do you have strong feelings about the veterans being remembered?” an older Friend asked Linda.

Because she has been given the opportunity to release, Linda was able to move with the meeting toward clarity. "No, I have no objection to the men being remembered," she said.

"Might we allow them to decorate the graves but leave their guns outside?" suggested the older Friend. Another Friend responded, "I can approve of that if it is acceptable to Linda."

"Yes,” said Linda, "I would find that acceptable.” The meeting fell silent and then adjourned.

That simple resolution almost seemed like a compromise. But a year later, when no one expected it, Linda reported to the meeting that she had visited the graveyard on Memorial Day to check on the veterans. "They left their guns outside when they went in,” she said. The silence that followed amplified the sense of unity we had felt a year earlier.

From this example, the sense of an unfolding unity can help to be appreciated, as well as the faith and discipline in the business method. This involves starting by giving people space to 'vent' their views, then as the dialogue unfolds a calmer space is needed to relate with what 
each person brings to the process. There is a close attention to the differing views expressed, as well as how they are held, and their relation to others in the group. Unknowing, where nobody individually understands the meaning of the situation nor has an answer, is an accepted and core aspect of being in conversation, which supports a patient and frequently silent searching for how to go on together. Consequently, potential feelings of anxiety and discomfort, which as explored can be disruptive to reflexive practice, are likely negated as individual unknowing is an expected quality of conversing. The members of the group are subordinate to the collective processes of seeking unity in ways forward, through which ideas are iteratively tested, revised and woven together.

The relational dynamics involved in Meetings for Business are complex and nuanced. These are inevitably flattened out in any example. For instance, in the Meetings for Business in which I have participated, in seeking to achieve sense of the meeting I have noticed a sense of waiting among those present. The waiting appears to have various dimensions. Firstly, it relates to taking care with the process, making sure that the business method is being respected, which might involve some Friends seeking reassurance from those more experienced that we are promoting equity and unity in dialogue. Secondly, is a preoccupied or worried waiting, which is about issues on the agenda to be discussed and the associated concerns, disagreements or actions that could emerge. Thirdly, is a frustrated dimension, where there is an impatient sense of waiting that we need to work through the agenda more quickly, some annoyance that the process can be overly deliberative and laborious in making decisions about at times minor administrative issues. This frustrated dimension has been mirrored, and potentially reinforced, by sporadic apologies from the Clerk(s) about the duration of the meeting.

From these dimensions about waiting we can appreciate that, like any process of organising, there are various potential dynamics of resistance and disenchantment with the way Meetings for Business can be conducted and their outcomes. For instance, the discerned way forward is recorded in a minute with the related action falling to a person or a few people to enact. This means that any action may take alternative shape in practice based on the individual's preferences and skills, or shifting circumstances which change the potential to carry out the decision which has been discerned. This collective-knowing - individual-acting gap may mean that decisions in practice, by having a rigid action logic through how they are specified in the related minute, can remove possibilities for generative learning in action. In the case that the decision becomes inappropriate due to changing circumstances, then the need can arise to postpone any movement forwards until further collective discernment can be given space to occur at the next Meeting for Business, which are typically monthly. Such dynamics can annoy those who feel a pressure to respond to what may be understood to be pressing issues.

Through this analysis of others' experiences and my own it is clear that the Quaker approach is not a solution to be instrumentally adopted in any situation, as it "cannot be simplified into one of mere procedure” (Pollard, Pollard, \& Pollard, 1949, p. 71). Crucially the Quaker business method is something that as Bradney \& Cownie suggest "is an integral part of a worshipping community, composed of individuals who know each other well and trust one another on a spiritual level” (2000, p. 79). Additionally, we must be careful not to take an idealised view of this community and its practices, as Cranmer suggests "business meetings are by no means immune from manipulation and Friends are no more saintly than anyone else” (2003, p. 188). For example, a key potential issue relates to judgements about the value of each others' views, and dimensions of each person's unknowing, as to how the different 
voices can be brought together into collective knowing. Relational patterns may become established in such a community which means that particular individuals' contributions are marginalised based on their experience with the 'business method', or more general perceptions about the qualities of their insights and intentions. However, as Rack comments about the business method "it doesn't always work in practice and sometimes it fails catastrophically, but the wonder is that actually it does work quite well, quite often” (2002, p. 23).

By embracing ideas of a perpetual individual unknowing I am offering a new perspective to debates about reflexive practice which draws upon ideas of a relational ontology where knowing is understood as achieved through collective processes (Gergen, 2009; Hosking, 2011). This perspective offers an alternative view to other conceptualisations of reflexive practice as they suggest a potential to shift between moments of individual knowing and notknowing (Keevers \& Treleaven, 2011; Marshall, 1999; Marshall \& Reason, 2007; Segal, 2010). The implication of this new perspective is that because the individual knower is decentred, being reflexive can be understood as involving practices of embracing individual unknowing so that collective knowing about being together in a world can be fostered. Whereas Xing and Sims describe a reflexive individual leadership practice in reference to the concept of Wu Wei as involving "being concentrated in flow" and not "forc[ing] the situation” (Xing \& Sims, 2012, p. 110), I am offering images of collective processes of being in the flow together.

The implications for living and managing extend from existing suggestions about what can be understood from processes of Quaker organising. By embracing individual unknowing as an inevitable part of being in the world, this new perspective helps give more texture to practices of 'humility' (Reis Louis, 1994) and 'fluidity' (Law \& Mol, 2003). In particular, appreciating how we might conduct ourselves, and the different types of formal or informal roles we might take, in the relational dance of searching for collectively intelligent ways forward. Ways which involve engaging in, and experimenting with, the communicative potential of collective 'silences' for respecting peoples' different insights and perspectives (MolinaMarkham, 2014). As explored, silences are central in enacting the collective processes involved in the business method as they continually reaffirm the limitations of any individuals' knowing. Finally, there are implications for practices of minute taking, and how minutes are involved in processes of organising and being reflexive. In the Quaker business method finalising a minute for each issue considered is not only a ritual which signifies the ending of a discussion, but the text that is crafted inscribes and legitimates the processes of spiritual discernment through which a unity was achieved. Consequently, a minute's meaning and value extend beyond the contextualisation and administrative arrangements that it explains.

\section{Closing comments}

What I have sought to show is the compatibility of Quaker processes with reflexive practice and to highlight the possibilities to learn from this 350 year old approach in respect of embracing unknowing. Much of the connectivity is between Quakers' striving for equality in relations, and an ongoing preoccupation in research about reflexive practice to understand how approaches to managing can be emancipatory (Barge, 2004; Cunliffe, 2004; Hibbert \& Cunliffe, 2015). Reciprocally there are opportunities for Quakers to learn from the work in organisational and management studies on reflexive practice, particularly in relation to understanding the potential dynamics and complexities of ideas about power and politics within relationships. For instance, helping to appreciate the taken-for-granted aspects of our 
(collective) views and how they can shape our sense-making and restrict our visibility.

I have argued that appreciating an unresolvable unknowability is fundamentally important for being reflexive. By exploring how the collective processes of the Quaker business method encourage individual unknowing I have offered a new perspective on reflexive practice. I have achieved this by arguing that a 'relational ontology' informed approach can offer a suitable bridge to bring Quaker spirituality into conversation with discussions about reflexive practice (Gergen \& Hosking, 2006; Hosking, 2012). By developing this perspective on reflexive practice we centre the limits of our cognitive potential and focus attention on the value of being subordinated to a more intelligent collective, respectful and equitable knowing. The Quaker Meeting for Business can be understood as a way of bringing different ideas and images to help imagine the possibilities for embracing individual unknowing in support of collectively finding ways forward in a diversity of settings. In this case Quaker spirituality has been offered as a vocabulary for exploring unknowing, but that does not preclude enabling relational ontologic sensibilities for systemic interconnectivity without understanding yourself as 'being spiritual'. For example, although Law and Mol (2003) consider connected dynamics they do so by taking an approach to relationality which is not explicitly spiritually engaged.

Going back to my opening vignette, realising these possibilities may seem hard to imagine in many organisational contexts, but my key contention is that they are worthy of striving for, and can be a potent resource to draw upon to extend the meanings and practices of managing reflexively. There are many potential opportunities for studying the alternative processes of Quaker communities, such as: how Quakers learn to participate in the business method, in what ways Quaker practices might relate to notions of mindfulness, and the role of different types of silences in being reflexive. I hope that this paper will help promote interest in doing so.

\section{References}

Ambler, R. (2013). The Quaker way a rediscovery. Winchester: Christian Alternative.

Antonacopoulou, E. P. (2004). The dynamics of reflexive practice: The relationship between learning and changing. In M. Reynolds \& R. Vince (Eds.), Organizing reflection (pp. 47-64).

Barge, J. K. (2004). Reflexivity and managerial practice. Communication Monographs, 71(1), 70-96.

Bateson, G. (1979). Mind and nature: a necessary unity. London: Wildwood House.

Bell, E. (2008). Towards a critical spirituality of organization. Culture and Organization, 14(3), 293.

Bleakley, A. (1999). From reflective practice to holistic reflexivity. Studies in Higher Education, 24(3), 315.

Bradney, A., \& Cownie, F. (2000). Living Without Law: An Ethnography of Quaker Decisionmaking, Dispute Avoidance, and Dispute Resolution. Dartmouth Publishing Company.

Castle, E. (1961). Approach to Quakerism. London: Fountian Press.

Corlett, S. (2013). Participant learning in and through research as reflexive dialogue: Being 'struck' and the effects of recall. Management Learning, 44(5), 453-469.

Cranmer, F. (2003). Regulation within the Religious Society of Friends. Ecclesiastical Law Journal, 7(33), 176-194.

Cunliffe, A. L. (2002). Reflexive dialogical practice in management learning. Management Learning, 33(1), 35-61.

Cunliffe, A. L. (2004). On Becoming a Critically Reflexive Practitioner. Journal of 
Management Education, 28(4), 407-426.

Cunliffe, A. L. (2009). Reflexivity, learning and reflexive practice. In S. Armstrong \& C. Fukami (Eds.), The Sage Handbook of Management Learning, Education and Development. London: Sage.

Dandelion, P. (2008). The Quakers: A very short introduction. Oxford University Press.

Doncaster, H. (1958). Quaker organisation and business meetings. London: Friends Home Service Committee.

Durham, G. (2010). The spirit of the Quakers. London: Yale University Press.

Gergen, K. (2009). Relational being: beyond self and community. Oxford: Oxford University Press.

Gergen, K., \& Hosking, D. M. (2006). If you meet social construction along the road: A dialogue with Buddhism. In M. Kwee, K. Gergen, \& F. Koshikawa (Eds.), Horizons in Buddhist Psychology (pp. 299-314). Chagrin Falls, Ohio: Taos Institute Publications.

Halliday, R. (1991). Mind the oneness: the foundation of good Quaker business method. London: Quaker Home Service.

Hibbert, P., \& Cunliffe, A. L. (2015). Responsible Management: Engaging Moral Reflexive Practice Through Threshold Concepts. Journal of Business Ethics, 127(1), 177-188.

Hosking, D. M. (2011). Telling Tales of Relations: Appreciating Relational Constructionism. Organization Studies, 32(1), 47-65.

Hosking, D. M. (2012). Organizing a Buddhist Way. In P. Case, H. Höpfl, \& H. Letiche (Eds.), Belief and Organization (pp. 69-89). New York: Palgrave Macmillan.

Hosking, D. M., \& Pluut, B. (2010). (Re) constructing reflexivity: a relational constructionist approach. The Qualitative Report, 15(1), 59-75.

Izak, M. (2009). Spirituality in organization: a dubious idea (?) Historically oriented sensemaking in spiritually imbued organizations. Tamara Journal for Critical Organization Inquiry, 8(2).

Kavanagh, J. (2015). A little book of unknowing. Winchester: Christian Alternative.

Keevers, L., \& Treleaven, L. (2011). Organizing practices of reflection: A practice-based study. Management Learning, 42(5), 505-520.

Law, J., \& Mol, A. (2003). On Metrics and Fluids: Notes on Otherness. In R. Chia (Ed.), Organized Worlds: Explorations in Technology and Organization with Robert Cooper. Routledge.

Lawson, H. (1985). Reflexivity: the post-modern predicament. La Salle: Open Court.

Lynch, M. (2000). Against Reflexivity as an Academic Virtue and Source of Privileged Knowledge. Theory, Culture \& Society, 17(3), 26-54.

Mace, J. (2012). God and decision making a Quaker approach. London: Quaker Books. Marshall, J. (1999). Living Life as Inquiry. Systemic Practice and Action Research, 12(2), 155-172.

Marshall, J., \& Reason, P. (2007). Quality in research as 'taking an attitude of inquiry'. Management Research News, 30(5), 368-380.

Miehls, D. (2000). Constructing social work identity based on the reflexive self. British Journal of Social Work, 30(3), 339-348.

Molina-Markham, E. (2014). Finding the 'Sense of the Meeting': Decision Making Through Silence Among Quakers. Western Journal of Communication, 78(2), 155.

Morley, B. (1993). Beyond consensus: salvaging sense of the meeting. Pennsylvania: Pendle Hill Publications.

Pillow, W. (2003). Confession, catharsis, or cure? Rethinking the uses of reflexivity as methodological power in qualitative research. International Journal of Qualitative Studies in Education, 16(2), 175-196. 
Polanyi, M. (1962). Personal knowledge: towards a post-critical philosophy. London: Routledge \& Kegan Paul.

Pollard, F. E., Pollard, B. E., \& Pollard, R. S. (1949). Democracy and the quaker method. London: The Bannisdale Press.

Rack, P. (2002). Quakerism in the 21st Century. York, England: William Sessions Limited.

Reis Louis, M. (1994). In the Manner of Friends: Learnings from Quaker Practice for Organizational Renewal. Journal of Organizational Change Management, 7(1), 4260.

Segal, S. (2010). A Heideggerian approach to practice-based reflexivity. Management Learning, 41(4), 379-389.

Sharman, C. (1983). Servant of the meeting: Quaker business meetings and their clerks. London: Quaker Home Service.

Sheeran, M. (1983). Beyond majority rule: voteless decisions in the Religious Society of Friends. Philadelphia: Philiadelphia Yearly Meeting of the Religious Society of Friends.

Windsor, D. B. (1980). The Quaker enterprise: Friends in business. London: Muller.

Xing, Y., \& Sims, D. (2012). Leadership, Daoist Wu Wei and reflexivity: Flow, selfprotection and excuse in Chinese bank managers' leadership practice. Management Learning, 43(1), 97-112.

Zembylas, M. (2005). A Pedagogy of Unknowing: Witnessing Unknowability in Teaching and Learning. Studies in Philosophy and Education, 24(2), 139-160. 